\title{
A Population Perspective on Prevention of Dementia
}

\author{
Esmé Eggink ${ }^{1, *}$, Eric P. Moll van Charante ${ }^{1}{ }^{1}$, Willem A. van Gool ${ }^{2}$ and Edo Richard ${ }^{2,3}$ \\ 1 Department of General Practice, Amsterdam University Medical Center, University of Amsterdam, \\ Meibergdreef 15, 1105 AZ Amsterdam, The Netherlands; e.p.mollvancharante@amc.uva.nl \\ 2 Department of Neurology, Amsterdam University Medical Center, University of Amsterdam, \\ Meibergdreef 15, 1105 AZ Amsterdam, The Netherlands; w.a.vangool@amc.uva.nl (W.A.v.G.); \\ e.richard@amc.uva.nl (E.R.) \\ 3 Department of Neurology, Donders Institute for Brain, Behaviour and Cognition, Radboud University \\ Medical Center, Geert Grooteplein Zuid 10, 6525 GA Nijmegen, The Netherlands \\ * Correspondence: e.eggink@amc.uva.nl
}

Received: 15 May 2019; Accepted: 9 June 2019; Published: 12 June 2019

\begin{abstract}
The global number of people living with dementia is expected to increase to 130 million in 2050. Based on extensive evidence from observational studies, it is estimated that about $30 \%$ of dementia cases may be attributable to potentially modifiable risk factors. This suggests that interventions targeting these factors could perhaps delay or prevent the onset of dementia. Since the vast majority of people with dementia live in low- and middle-income countries, such interventions should preferably be easy and affordable to implement across a wide range of health care systems. However, to date, results from dementia prevention trials do not provide convincing evidence that treatment of these risk factors reduces the risk of dementia. The current paper aims to give an overview of available evidence for the potential for dementia prevention. In particular, we discuss methodological issues that might complicate the development of effective prevention interventions and explore the opportunities and challenges for future dementia prevention research. Currently, several ongoing and planned trials are testing the effect of multi-domain interventions on dementia risk in high-risk populations. It is desirable that future dementia strategies also target the wider population, through interventions on the individual, community, and population level, in order to constrain the growing prevalence of dementia worldwide.
\end{abstract}

Keywords: dementia prevention; Alzheimer's disease; vascular risk factors; multi-domain interventions; public health

\section{Changing Perspectives on Late-Life Dementia}

The clinical picture of dementia has been recognized for centuries, but throughout time the theories on its causes have varied widely. Dementia received specific attention in 1907, when Alois Alzheimer wrote his famous case report "About a peculiar disease of the cerebral cortex" [1]. His findings of plaques and tangles in the brain of a 51-year old patient with progressive cognitive problems were included in a leading psychiatry textbook by Emil Kraepelin, and the condition was referred to with the term "Alzheimer's disease" (AD) [2]. From then on, AD was considered to be a rare condition, causing dementia through plaques and tangles in relatively young people. Cognitive decline in the last decades of life, at the time referred to as senile dementia, was considered to be attributable to atherosclerosis, and stroke and was thought of as a distinct condition [3].

From the early seventies onwards, perceptions of the pathogenesis of senile dementia shifted from vascular mechanisms to $\mathrm{AD}$ pathology, based on the discovery of extensive amounts of extracellular amyloid depositions (plaques) and intracellular depositions of hyperphosphorylated tau-protein (tangles) in the brains of older people with dementia [4]. Consequently, the sharp distinction between presenile and senile dementia faded. In the early nineties, it was discovered that the specific e4 allele of Apolipoprotein 
E (APOE $\varepsilon 4$ ) was associated with both early- and late-onset dementia $[5,6]$, supporting the hypothesis that Alzheimer's disease was the predominant cause of both early- and late-onset dementia. At this time, vascular dementia was still considered a separate, less frequent cause of dementia.

The role of vascular pathology in the development of late-life dementia regained interest in the late nineties, when several epidemiologic and radiologic studies reported a strong relationship of cardiovascular risk factors and disease with impaired cognitive functioning $[7,8]$. These findings were supported by neuropathological findings. Examination of the brains of 102 elderly nuns suggested a strong interaction effect on cognitive functioning between the presence of AD pathology and lacunar strokes [9]. A large autopsy study in a population-based cohort in the United Kingdom, with a median age of 85 at death, showed that most dementia patients had a mixture of cerebrovascular and AD pathology, whereas subjects without dementia often had a considerable level of pathologies as well, or no pathologies at all [10]. Since then, numerous epidemiologic studies have investigated the relationship between vascular risk factors or vascular disease, and stroke development, and late life dementia [11-13]. Based on several more recent studies, it is perceived that the presence and mutual interaction of genetic factors, such as carrying the APOE $\varepsilon 4$ allele, and vascular factors are involved in the development of multiple brain pathologies, including amyloid plaques, tangles containing hyperphosphorylated tau, and different vascular lesions [14-16]. These brain pathologies all increase the likelihood to develop mild cognitive impairment (MCI) and dementia [17], but they are not sufficient to fully explain either onset, course, or specific clinical symptoms.

\section{Exploring the Window of Opportunity for Dementia Prevention}

The concept of dementia caused by multifaceted brain disease implies a wide range of possible strategies for dementia prevention and treatment. The need for such strategies is emphasized by the large number of people living with dementia worldwide, which is expected to rise from 47 million in 2015 to over 130 million in 2050, largely due to the increasing life expectancy [18]. It is estimated that $90 \%$ of dementia patients are older than 75 years, and $75 \%$ are older than 80 years of age [19]. Strategies to prevent dementia among people without the disease could perhaps delay its onset and reduce the prevalence of dementia [20]. Since it is expected that by $205068 \%$ of all people with dementia live in low- and middle-income countries (LMIC) [18], such strategies should ideally be easy and inexpensive to implement on a large scale across a wide variety of health care systems.

Observational studies suggest a number of modifiable factors that are associated with dementia risk and could serve as a target for prevention. Elevated blood pressure, body mass index (BMI), elevated total cholesterol levels [21-26], diabetes mellitus [27], current smoking [28], depression [29], physical inactivity [30], cognitive inactivity [31], poor diet [32], and low educational attainment [33] are well-established factors that are independently associated with an increased risk of dementia. Even small improvements of the modifiable dementia risk factors on the individual level have the potential to lead to a substantial reduction of dementia cases at the population level, due to the high global prevalence of these risk factors [34]. By calculating population-attributable risks for seven well-established dementia risk factors (diabetes mellitus, midlife hypertension, midlife obesity, physical inactivity, depression, smoking, and low educational attainment), and taking inter-relatedness into account, it was estimated that $30 \%$ of all dementia cases worldwide can be attributed to these potentially modifiable risk factors [35], with low educational attainment, smoking, and physical inactivity carrying the strongest risk. This suggests a large window of opportunity for dementia prevention.

The high prevalence of these modifiable factors raises the question of whether population-based prevention strategies could reduce the prevalence of dementia. Over the years, many community programs have been designed to reduce cardiovascular disease (CVD) risk. Controlled before-after studies have shown that, in general, these programs can be effective at improving cardiovascular risk factors and, in some cases, reducing incident CVD and mortality [36]. Although risk factors are largely similar for CVD and dementia, no comparable studies have been performed to study the effect of community prevention programs on cognitive functioning or dementia. However, five large studies have compared dementia 
occurrence between two time points in well-defined geographical areas. Four of five studies showed a slight reduction of dementia prevalence, which could potentially be attributed to population-level investments, including improved education and better prevention and treatment of vascular conditions [37].

\section{Dementia Prevention Trials}

In the last two decades, several intervention studies have been performed to test the hypothesis that dementia can be delayed or prevented by improving individual risk factors or the overall dementia risk profile in people free from cognitive impairment at baseline. We distinguish single-domain interventions, targeting a single risk factor, and multi-domain interventions, targeting multiple dementia risk factors simultaneously. Below, we will discuss these studies with dementia as a primary or secondary outcome.

\subsection{Single-Domain Interventions}

Although the list of potential interventions is very long [38], we will restrict our overview to the interventions for which most robust evidence from clinical trials and meta-analyses is available. As such, we do not intend to be exhaustive here.

Treatment of hypertension may reduce the risk of dementia via blood pressure lowering mechanisms, but also through other, perhaps antihypertensive class-specific, effects [21,39-41]. Results of hypertension trials have been encouraging, but are still inconclusive. A meta-analysis of four placebo-controlled trials of antihypertensive treatment with incident dementia as a primary outcome showed a combined risk ratio of 0.87 (95\% CI 0.76 to $1.00 ; N=16,595$ individuals; $n=786$ dementia cases), favoring treatment [42]. A more recent meta-analysis included nine blood pressure-lowering trials, including two lifestyle interventions, with a median follow-up of 3.9 years. The pooled risk ratio for incident dementia was 0.93 (95\% CI 0.84 to $1.02 ; N=57,682 ; n=2131$ dementia cases) [43]. The recently published Systolic Blood Pressure Intervention Trial: Memory and Cognition in Decreased Hypertension sub-study (SPRINT-MIND) assessed whether intensive blood pressure treatment with any agent, aiming for levels lower than $120 \mathrm{mmHg}$, could reduce incident dementia compared with standard blood pressure control, aiming for levels lower than $140 \mathrm{mmHg}$, in over 9000 patients (50+) with hypertension. The trial was ended prematurely because of beneficial effects on cardiovascular events and all-cause mortality in the intervention group. Pre-planned secondary analyses showed no significant effect on probable dementia (HR 0.83 ; CI 0.67 to $1.04 ; N=8563 ; n=325$ dementia cases), but a significant reduction of incident MCI (HR 0.81; CI 0.69 to $0.95 ; N=8563 ; n=640$ probable MCI cases) after a median intervention period of 3.3 years and a median follow-up period of 5.1 years [44]. Taken together, despite promising results from observational studies [21], these two meta-analyses and recent RCT failed to provide convincing evidence that dementia can be delayed or prevented with blood pressure treatment, but point estimates consistently suggest a potential preventive effect.

Type 2 diabetes mellitus (T2DM) may increase dementia risk through different mechanisms including cerebrovascular damage, insulin resistance, and mitochondrial dysfunction $[45,46]$. A recent systematic review identified seven randomized controlled trials to assess the effects of different T2DM treatment strategies on cognitive function and incident dementia [47]. Three studies were included in the efficacy analyses and used cognitive function or incident dementia as outcome measure. All three studies were at unclear risk of bias. Two of these studies compared intensive glycemic control versus standard glycemic control $[48,49]$. There was no significant difference between the two groups with regard to the number of participants who declined by at least 3 points on the mini-mental state examination (MMSE) over five years (RR 0.98; CI 0.88 to 1.08; $N=11,140$ individuals; 1 study), incident dementia (RR 1.27; CI 0.87 to 1.85; $N=11,140$ individuals; $n=109$ dementia cases; 1 study) [49], or MMSE score after 40 months (MD $-0.01 ; \mathrm{CI}-0.18$ to $0.16 ; N=2794$ individuals; 1 study) [48]. The third study compared glibenclamide with repaglinide. After 12 months, a small advantage of glibenclamide on MMSE score was found (MD -0.90; CI -1.68 to $-0.12 ; N=156$ individuals; 1 study) [50].

Despite observational evidence [23,24], to date no trials have shown beneficial effects of cholesterol-lowering treatment on dementia risk. A systematic review identified two RCTs that 
compared the effect of a statin versus placebo on cognitive decline and incident dementia among individuals with increased cardiovascular risk. Both studies had a low risk of bias. No difference was found with regard to incident dementia (OR 1.00; CI 0.61 to $1.65 ; N=20,536 ; n=62$ dementia cases; 1 study) between simvastatin and placebo. No effect of simvastatin or pravastatin was found on cognitive function, assessed by five different cognitive tests [51]. According to current guidelines, a very high percentage of participants between 40 and 75 years old are eligible for statin prescription, with the aim to prevent cardiovascular disease [52]. Although the prevention of stroke can be expected to lower the risk of dementia, there is no direct evidence for this effect so far.

Physical activity is thought to decrease dementia risk through multiple mechanisms, including increased neurogenesis, angiogenesis, and synaptic plasticity and anti-inflammatory effects [53]. Moreover, physical activity can have beneficial effects on other factors that are associated with dementia risk, including obesity, dyslipidemia, and high blood pressure. A recent systematic review investigated 32 trials with a follow-up of more than 6 months, to assess the effectiveness of physical activity interventions on cognitive function among adults without a diagnosis of cognitive impairment. Included studies targeting only physical activity involved aerobic training (six studies, 531 individuals), resistance training (three trials, 315 individuals), and tai chi (one trial, 93 individuals). Evidence from these trials was insufficient to draw any conclusion about a beneficial effect on cognitive function [54]. Because of the beneficial effects of physical activity on obesity and the risk of CVD, public health campaigns and public health initiatives to facilitate physical activity are widely applied. To date, whether this will reduce the risk of dementia remains uncertain.

\subsection{Multi-Domain Interventions}

Exposure to a combination of modifiable dementia risk factors may have a synergistic effect on risk of cognitive decline and dementia [55,56]. Therefore, multi-domain interventions, targeting more than one risk factor, may be a more appropriate approach to study dementia prevention. In the past decade, several multi-domain trials have been performed, testing varying interventions across a wide range of sample sizes and follow-up times. We will discuss the main multi-domain intervention studies in terms of sample size and follow-up time with dementia, MCI, or cognitive decline as primary end-point (Table 1).

Table 1. Multi-domain dementia prevention trials.

\begin{tabular}{|c|c|c|c|}
\hline & preDIVA & FINGER & MAPT \\
\hline Age range & $70-78$ & $60-77$ & $70+$ \\
\hline Main inclusion criteria & Not demented ${ }^{b}$ & $\begin{array}{c}\text { Dementia risk score } \geq 6^{a} \\
\text { Cognitive performance at } \\
\text { mean or slightly lower level }\end{array}$ & $\begin{array}{l}\text { Not demented }{ }^{b} \\
\text { Memory complaints or limitations } \\
\text { in daily living or slow gait speed }\end{array}$ \\
\hline Intervention period & $6-8$ years & 2 years & 3 years \\
\hline Follow-up period & $6-8$ years & 2 years & 3 years \\
\hline
\end{tabular}

FINGER: Finnish Geriatric Intervention Study to Prevent Cognitive Impairment and Disability; MAPT: Multidomain Alzheimer Prevention Study; preDIVA: prevention of Dementia by Intensive Vascular Care. ${ }^{\text {a }}$ assessed with Cardiovascular Risk Factors, Aging, and Dementia (CAIDE) risk score; ${ }^{b}$ defined as no clinical diagnosis and a Mini-Mental State Examination $>23 ;{ }^{c}$ assessed with the neuropsychological test battery (NTB); ${ }^{d}$ assessed with

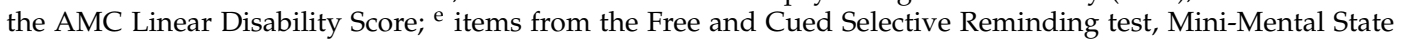
Examination, Digit Symbol Substitution Test, and Category Naming Test. 
The Dutch prevention of Dementia by Intensive Vascular Care (preDIVA) [57] cluster-randomized trial compared the effect of a 6-year, intensive, nurse-led multi-domain cardiovascular care intervention with usual care on the cumulative incidence of dementia and disability. 116 General practices were randomly assigned to one of the conditions. 3526 individuals without dementia, aged 70-78 years, participated. After a median follow-up of 6.7 years, primary outcome data were obtained in more than $98 \%$ of the participants. No significant effect was found of the intensive cardiovascular care on incident dementia (HR 0.92; CI 0.71 to $1.19 ; N=3454$ individuals; $n=233$ dementia cases) and disability.

The Finnish Geriatric Intervention Study to Prevent Cognitive Impairment and Disability (FINGER) [58] compared the effect of a multi-domain intervention, including nutritional guidance, physical activity, cognitive training, and monitoring of modifiable dementia risk factors, with general health advice (control group) on cognitive function, assessed with an extensive neuropsychological test battery (NTB). 1260 Individuals without dementia, aged 60-77 years, with an increased dementia risk in terms of 6 or more points on the Cardiovascular Risk Factors, Aging and Dementia (CAIDE) risk score, were randomly assigned to either of the treatment arms. After two years, the intervention group showed a slightly larger improvement on the standardized NTB compared with the control group (between-group difference in change score per year 0.022; CI 0.002 to $0.042 ; N=1190$ individuals).

The French Multidomain Alzheimer Preventive Trial (MAPT) [59] studied the effects of omega 3 polyunsaturated fatty acids and the effect of a multi-domain intervention, consisting of group sessions targeting cognitive training, physical activity, and nutrition on cognitive function. Participants were eligible when they were 70 years or older and either had subjective memory complaints, limitations in one instrumental activity of daily living, or slow walking speed. 1680 Participants were randomly assigned to one of four groups: the multi-domain intervention combined with omega 3 polyunsaturated fatty acids, the multi-domain intervention with placebo, and omega 3 polyunsaturated fatty acids with no other intervention or placebo alone. After three years, there were no significant differences in cognitive function, assessed with a composite score of four cognitive tests, between any of the treatment groups and the placebo alone group: between-group differences were 0.093 (95\% CI 0.001 to $0.184 ; N=$ 1525 individuals) for combined intervention, $0.079(95 \% \mathrm{CI}-0.012$ to $0.170 ; N=1525$ individuals) for the multi-domain intervention plus placebo group, and 0.011 (95\% CI -0.081 to $0.103 ; N=1525$ individuals) for the omega 3 polyunsaturated fatty acids group.

\section{Explaining the Gap between Observational and Interventional Studies}

A substantial gap exists between the results from many observational studies, suggesting optimism, and the rather sobering results from dementia prevention trials. Hence, it could be that vascular factors have an association, rather than a causal relationship, with dementia risk. However, most of Hill's criteria for causation, such as consistency and plausibility [60], are met. Although the current evidence does not support a protective effect of preventive interventions for dementia, particularly for hypertension, there is a rather consistent signal in the direction of a preventive effect. Moreover, it is conceivable that methodological issues, which have been associated with the design of dementia prevention trials [61-63], lead to type II errors, masking "true" effects of multi-domain interventions, and causing apparent inconsistency with observational evidence.

\subsection{Age of the Target Population and J-Shaped Curves}

An important issue when designing a dementia prevention trial is the optimal age range of the target population. A target population that is too young would require infeasible follow-up periods or sample sizes, due to the low incidence of dementia in younger age. Conversely, a target population that is too old would probably lead to decreased efficacy of the intervention, because the relationship between some risk factors and dementia becomes more complex with age [63]. The association between blood pressure during late-life and dementia is suggested to follow a U- or J-shaped curve, with both high and low values imposing increased dementia risk [64]. This is consistent with ample research on the relationship between blood pressure and cardiovascular disease [65]. With regard to BMI, 
a similar J-shaped relation with dementia risk is suggested in late-life, with elevated BMI levels being associated with lower, and being underweight with increased, dementia risk [66], suggesting a similar type of J-shaped curve as with blood pressure. Likewise, high total serum cholesterol concentrations in late-life have been associated with decreased dementia risk [24,67]. It is unclear when the directions of these associations change. Nevertheless, it is conceivable that the target populations from the three multi-domain interventions described above, with age-ranges 60-77, 70+, and 70-78 years, respectively, were too old to benefit from the interventions. These complex relationships pose a major challenge for future dementia prevention trials. Clearly, one size does not fit all, but with regard to age it is currently unclear what the optimal target values for blood pressure, BMI, and cholesterol might be.

\subsection{Risk Profile of the Target Population}

The level of quality and accessibility of standard preventive care that is available for the target population affects the degree of contrast a trial may yield. Subgroup analyses of the preDIVA study show the strongest effects of the intervention in participants with untreated hypertension and in participants without history of cardiovascular disease [57]. It could well be that an effect of the intervention was not found in the three multi-domain intervention trials, because high-quality cardiovascular risk management was already available for both intervention and control participants. As such, future studies may need to target populations at high risk who lack access to high-quality preventive health care. Policymakers and health organisations alike may need to actively target those persons that are typically not represented in clinical trials, but are at highest risk.

\subsection{Hawthorne and Treatment Effects in the Control Condition}

Another challenge is the observed improvement on primary and secondary outcomes of the control group in some multi-domain intervention studies $[57,58]$. This is illustrated by the decrease in blood pressure in both study arms of the preDIVA trial. The mean difference in systolic blood pressure between baseline and follow-up was $8.3 \mathrm{mmHg}$ in the intervention group and $4.6 \mathrm{mmHg}$ in the control group, suggesting initiation of treatment by a general practitioner or specialist or changes in lifestyle behaviour by the participant following the baseline measurements. Additionally, changed behaviour of participants or healthcare professionals as a reaction to the awareness of the study (Hawthorne effect) is likely to play a role [68]. Both mechanisms could mask the "true" contrast between the intervention and control condition, leading to type II errors.

\subsection{Competing Risk of Death}

Age is the most important risk factor for dementia. Starting at the age of 60 , the incidence of dementia doubles with every 6.3 years increase in age [18]. It is likely that, due to shared risk factors, dementia prevention trials have beneficial effects on cardiovascular endpoints, and, as a consequence, on mortality. Therefore, effective multifactorial interventions could paradoxically increase dementia incidence rates when death is delayed. If not taken into account, this could lead to serious underestimation of the effectiveness of dementia prevention interventions.

\section{Future Directions}

\subsection{Strategies to Deal with Limited Statistical Power}

When designing dementia prevention trials, sufficiently large sample sizes and/or long follow-up periods are paramount to reach statistical power, due to the time lag between the optimal timing of the intervention and dementia onset. Hence, given these preconditions, funding dementia prevention trials will remain a daunting challenge.

One potential approach towards longer follow-up is open label extension of studies, as was done in the Syst-Eur trial [13]. However, selective attrition will be a complicating factor for such observational extensions. Another strategy to overcome lack of power is to collaborate with other (international) 
research groups, enabling the design of multi-national trials and pooling of data of previous trials where possible and appropriate. An example is the European Dementia Prevention Initiative (EDPI) consortium, a collaboration of five European institutes, including the three research groups involved in the FINGER, MAPT, and preDIVA trials, respectively [69]. A third strategy could involve selection of a primary outcome that is likely to emerge earlier in life than dementia onset. Examples are cognitive impairment, existing dementia risk scores, or biomarkers presumed to reflect biological processes eventually leading to dementia. However, the uncertain association between biomarkers and cognition renders this a suboptimal primary outcome with regard to clinical relevance. A fourth solution could be to exclusively target individuals with an increased dementia risk who are still free from cognitive impairments. Numerous strategies exist to estimate dementia risk, including the use of biomarkers, imaging [70], family history [71], and dementia risk scores [72,73]. Obviously, from a population perspective, the use of (invasive) biomarkers is not feasible, certainly not in LMIC, but simple and readily available risk markers such as a positive family history or the presence of multiple dementia risk factors can be applied on a large scale at low cost. Some researchers have also used signs of cognitive decline to indicate high dementia risk. However, the latter approach is accompanied by a relatively high risk of including individuals with an early stage of dementia, in whom the intervention is less likely to be effective [74]. A fifth approach could be to target populations with poor access to preventive healthcare quality, such as in LMIC. These populations could be a promising target for lifestyle interventions, since the incidence of dementia is relatively high and the peak incidence is at younger age than in high-income countries (HIC) [18]. Moreover, the prevalence of dementia risk factors in these countries is higher than in HIC [75].

\subsection{Ongoing and Planned Multi-Domain Dementia Prevention Trials}

For successful implementation in LMIC, dementia prevention interventions should ideally be easily available, accessible, and affordable. These criteria are often met by web-based interventions, such as electronic health (eHealth) and mobile health (mHealth), especially because the majority of the world population uses internet these days and in countries with limited internet access it is increasing rapidly [76]. Four currently ongoing or planned multi-domain interventions will be testing the effectiveness of such digital dementia prevention interventions (Table 2).

The ongoing multi-national Healthy Aging Through Internet Counselling in the Elderly (HATICE) trial, performed by the EDPI consortium, is comparing a coach-supported, interactive internet platform, stimulating self-management of cardiovascular risk factors, with a sham platform without interactive features, for 18 months. The study population consists of approximately 2724 individuals, aged 65 years or older, and with an increased cardiovascular risk. The primary endpoint is a composite cardiovascular risk score, including systolic blood pressure, low-density-lipoprotein, and BMI. Cognitive function is a secondary outcome [77].

An ongoing cluster-randomized trial in Thailand with 3600 participants is comparing a three-year digital, coach-supported lifestyle modification intervention on four domains (diet, physical activity, alcohol drinking, and smoking) with care as usual. Participants are eligible when they are between 45 and 75 years of age and do not have a diagnosis of dementia, chronic kidney disease, diabetes, chronic obstructive pulmonary disease, cancer, or CVD. The primary outcome, measured after ten years, is incident dementia. Cognitive function, assessed with the MMSE, is one of the secondary outcomes [78].

The Maintain Your Brain (MYB) trial is comparing a digital platform with interactive modules on physical activity, diet, mental health, and cognitive training with a digital platform containing static information about dementia risk factors. The study population will consist of approximately 8500 individuals, recruited through an existing Australian cohort of non-demented community dwelling individuals aged between 55 and 77 years. The primary outcome, measured after three years, is cognitive change on a composite score of cognitive functioning. Secondary outcomes are incident dementia and change in dementia risk [79]. 
The planned Prevention Of Dementia Through Mobile Phone Applications (PRODEMOS) trial, initiated by the EDPI consortium, takes place in the United Kingdom (UK) and in Beijing, China [80]. A total of 2400 individuals, aged 55-75 years, with an increased dementia risk profile, and of low socioeconomic status in the UK, are randomized between a coach supported, interactive smartphone application, stimulating self-management of dementia risk factors; and a sham application without interactive features. The primary endpoint, measured after 18 months, is the CAIDE dementia risk score.

World Wide Fingers is an interdisciplinary network that arose from the FINGER trial. The multi-domain lifestyle intervention showed a modest beneficial effect on cognitive function after two years in a Finnish geriatric population. The same intervention is going to be tested in the United States, in rural China, in Singapore, and in several European countries [81].

Table 2. Planned and ongoing multi-domain dementia prevention trials.

\begin{tabular}{|c|c|c|c|c|}
\hline & HATICE & $\begin{array}{c}\text { Impact of Lifestyle } \\
\text { Modification on } \\
\text { Prevention of Dementia }\end{array}$ & MYB & PRODEMOS \\
\hline Start of recruitment & March 2015 & March 2016 & May 2018 & January 2020 \\
\hline Sample size & 2724 & 3600 & 8500 & 2400 \\
\hline $\begin{array}{l}\text { Recruiting } \\
\text { countries }\end{array}$ & $\begin{array}{l}\text { The Netherlands, } \\
\text { Finland, France }\end{array}$ & Thailand & Australia & $\begin{array}{l}\text { United Kingdom, } \\
\text { China }\end{array}$ \\
\hline Age range & $65+$ & $45-75$ & $55-77$ & $55-75$ \\
\hline $\begin{array}{l}\text { Main inclusion } \\
\text { criteria }\end{array}$ & $\begin{array}{l}\text { Not demented a } \\
\geq 2 \text { cardiovascular } \\
\text { risk factors }\end{array}$ & $\begin{array}{c}\text { Thai nationality, } \\
\text { no diagnosis of } \\
\text { dementia, diabetes, } \\
\text { COPD, cancer, or CVD }\end{array}$ & $\begin{array}{c}\text { No diagnosis of } \\
\text { dementia or severe } \\
\text { depression }\end{array}$ & $\begin{array}{l}\text { Not demented }{ }^{a}, \\
\geq 2 \text { dementia risk } \\
\text { factors }\end{array}$ \\
\hline Intervention & $\begin{array}{l}\text { Coach-supported } \\
\text { Internet platform for } \\
\text { self-management of } \\
\text { cardiovascular risk } \\
\text { factors }\end{array}$ & $\begin{array}{l}\text { Coach-supported } \\
\text { computer program on } \\
\text { diet, physical activity, } \\
\text { alcohol drinking, } \\
\text { and smoking }\end{array}$ & $\begin{array}{l}\text { Digital modules on } \\
\text { physical activity, } \\
\text { nutrition, peace of } \\
\text { mind, and brain } \\
\text { training }\end{array}$ & $\begin{array}{l}\text { Coach-supported } \\
\text { smartphone app for } \\
\text { self-management of } \\
\text { dementia risk factors }\end{array}$ \\
\hline Intervention period & 1.5 years & 3 years & 3 years & 1.5 years \\
\hline Follow-up period & 1.5 years & 10 years & 3 years & 1.5 years \\
\hline Primary outcome & $\begin{array}{l}\text { Composite } z \text {-score of } \\
\text { SBP, LDL cholesterol, } \\
\text { and BMI }\end{array}$ & Incident dementia & $\begin{array}{l}\text { Global cognition } \\
\text { composite domain } \\
\text { score }^{b}\end{array}$ & $\begin{array}{l}\text { CAIDE score, } \\
\text { implementation } \\
\text { outcomes }\end{array}$ \\
\hline $\begin{array}{l}\text { Main secondary } \\
\text { outcomes }\end{array}$ & $\begin{array}{l}\text { Individual factors } \\
\text { from composite } \\
\text { score, incident CVD }\end{array}$ & $\begin{array}{c}\text { Incident T2DM, CVD, } \\
\text { cancer, COPD, mortality }\end{array}$ & $\begin{array}{l}\text { Incident dementia, } \\
\text { dementia risk }\end{array}$ & $\begin{array}{c}\text { Individual components } \\
\text { of CAIDE score, } \\
\text { disability, } \\
\text { cost-effectiveness }\end{array}$ \\
\hline
\end{tabular}

BMI: body mass index; CAIDE: Cardiovascular Risk Factors, Aging, and Dementia risk score; COPD: chronic obstructive pulmonary disease; CVD: cardiovascular disease; HATICE: Healthy Aging Through Internet Counselling in the Elderly; Impact of Lifestyle Modification on Prevention of Dementia: Impact of Lifestyle Modification on Prevention of Dementia, Chronic Kidney Disease, Diabetes, Chronic Obstructive Pulmonary Disease, Cancers, and Cardiovascular Disease in a Thai General Population: Cluster Randomized Controlled Trial; LDL: low-density lipoprotein; MYB: Maintain Your Brain; PRODEMOS: Prevention Of Dementia Through Mobile Phone Applications; SBP: systolic blood pressure; T2DM: type 2 diabetes mellitus. ${ }^{a}$ defined as Mini-Mental State Examination >23; ${ }^{\mathrm{b}}$ Maintain Your Brain Battery.

\subsection{Population-Based Approaches}

Most of the ongoing trials are testing individual interventions in specific high-risk populations. However, the majority of dementia cases occur in individuals with low or intermediate risk [82]. It is therefore desirable that future dementia prevention strategies also target the wider population. Interventions targeting (a subgroup of) the population as a whole require different strategies. In addition to the individual level, primary prevention can be delivered at the community or the population level. Public health interventions that target common risk factors, such as discouraging smoking 
and encouraging a healthier lifestyle, can be implemented at several levels, and may include media campaigns, legislative changes, and preventive measures in working spaces and the community. Evaluating the effects of such interventions is complex, and may require different approaches than the classical parallel group randomised controlled trial. In addition to alternative methodologies to evaluate effectiveness, measures related to implementation will have to be taken into account, and such studies may require alternative large-scale governmental funding. Since risk factors for dementia largely overlap with risk factors for CVD, implementation in existing healthcare would probably benefit from an integrated approach, targeting dementia, CVD, and other non-communicable diseases [83].

\section{Conclusions}

Although results from observational studies suggest optimism, to date, results from dementia-prevention trials do not provide convincing evidence that treatment of these risk factors reduces the risk of dementia. However, some interventions, especially in intensive hypertension management, appear promising in the reduction of dementia risk and cognitive decline. Taking into account that the majority of dementia cases occur in LMIC, interventions should be easy and affordable to implement. Currently, several ongoing trials are testing the effectiveness of eHealth and mHealth interventions in high-risk individuals. Further implementation research on broadly available preventive interventions in the general population is warranted, to achieve global impact on dementia prevalence.

Author Contributions: E.E., E.P.M.v.C., and E.R. designed the outlines of the paper, E.E. wrote the paper; and E.P.M.v.C., W.A.v.G., and E.R. improved and corrected the style of the article.

Conflicts of Interest: The authors declare no conflict of interest.

\section{References}

1. Alzheimer, A. Über eine eigenartige Erkrankung der Hirnrinde. Allg. Z. Psychiatr. 1907, 64, 146-148.

2. Berchtold, N.C.; Cotman, C.W. Evolution in the Conceptualization of Dementia and Alzheimer's Disease: Greco-Roman Period to the 1960s. Neurobiol. Aging 1998, 19, 173-189. [CrossRef]

3. Mast, H.; Tatemichi, T.K.; Mohr, J.P. Chronic brain ischemia: The contributions of Otto Binswanger and Alois Alzheimer to the mechanisms of vascular dementia. J. Neurol. Sci. 1995, 132, 4-10. [CrossRef]

4. Blessed, G.; Tomlinson, B.E.; Roth, M. The Association Between Quantitative Measures of Dementia and of Senile Change in the Cerebral Grey Matter of Elderly Subjects. Br. J. Psychiatry 1968, 114, 797-811. [CrossRef] [PubMed]

5. Strittmatter, W.J.; Weisgraber, K.H.; Huang, D.Y.; Dong, L.M.; Salvesen, G.S.; Pericak-Vance, M.; Schmechel, D.; Saunders, A.M.; Goldgaber, D.; Roses, A.D. Binding of human apolipoprotein E to synthetic amyloid beta peptide: Isoform-specific effects and implications for late-onset Alzheimer disease. Proc. Natl. Acad. Sci. USA 1993, 90, 8098-8102. [CrossRef] [PubMed]

6. van Duijn, M.; de Knijff, P.; Cruts, M.; Wehnert, A.; Havekes, L.M.; Hofman, A.; Van Broeckhoven, C. Apolipoprotein E4 allele in a population-based study of early-onset Alzheimer's disease. Nat. Genet. 1994, 7 , 74-78. [CrossRef] [PubMed]

7. Skoog, I.; Kalaria, R.N.; Breteler, M.M. Vascular factors and Alzheimer disease. Alzheimer Dis. Assoc. Disord. 1999, 13 (Suppl. 3), S106-S114. [CrossRef] [PubMed]

8. Skoog, I.; Nilsson, L.; Palmertz, B.; Andreasson, L.-A.; Svanborg, A. A Population-Based Study of Dementia in 85-Year-Olds. N. Engl. J. Med. 1993, 328, 153-158. [CrossRef]

9. Snowdon, D.A.; Greiner, L.H.; Mortimer, J.A.; Riley, K.P.; Greiner, P.A.; Markesbery, W.R. Brain Infarction and the Clinical Expression of Alzheimer Disease-Reply. JAMA 1997, 278, 114. [CrossRef]

10. Neuropathology Group of the Medical Research Council Cognitive Function and Ageing Study (MRCCFAS). Pathological correlates of late-onset dementia in a multicentre, community-based population in England and Wales. Neuropathology Group of the Medical Research Council Cognitive Function and Ageing Study (MRC CFAS). Lancet 2001, 357, 169-175.

11. Breteler, M.M. Vascular risk factors for Alzheimer's disease: An epidemiologic perspective. Neurobiol. Aging 2000, 21, 153-160. [CrossRef] 
12. Troncoso, J.C.; Zonderman, A.B.; Resnick, S.M.; Crain, B.; Pletnikova, O.; O’Brien, R.J. Effect of Infarcts on Dementia in the Baltimore Longitudinal Study of Aging. Ann. Neurol. 2008, 64, 168-176. [CrossRef] [PubMed]

13. Forette, F.; Seux, M.-L.; Staessen, J.A.; Thijs, L.; Babarskiene, M.-R.; Babeanu, S.; Bossini, A.; Fagard, R.; Gil-Extremera, B.; Laks, T.; et al. The Prevention of Dementia with Antihypertensive TreatmentNew Evidence From the Systolic Hypertension in Europe (Syst-Eur) Study. Arch. Intern. Med. 2002, 162, 2046-2052. [CrossRef] [PubMed]

14. Haroutunian, V.; Schnaider-Beeri, M.; Schmeidler, J.; Wysocki, M.; Purohit, D.P.; Perl, D.P.; Libow, L.S.; Lesser, G.T.; Maroukian, M.; Grossman, H.T. Role of the Neuropathology of Alzheimer Disease in Dementia in the Oldest-Old. Arch. Neurol. 2008, 65, 1211-1217. [CrossRef] [PubMed]

15. Cheng, D.; Huang, R.; Lanham, I.S.; Cathcart, H.M.; Howard, M.; Corder, E.H.; Poduslo, S.E. Functional interaction between APOE4 and LDL receptor isoforms in Alzheimer's disease. J. Med. Genet. 2005, 42, 129-131. [CrossRef] [PubMed]

16. Schneider, J.A.; Arvanitakis, Z.; Bang, W.; Bennett, D.A. Mixed brain pathologies account for most dementia cases in community-dwelling older persons. Neurology 2007, 69, 2197-2204. [CrossRef] [PubMed]

17. Schneider, J.A.; Arvanitakis, Z.; Leurgans, S.E.; Bennett, D.A. The neuropathology of probable Alzheimer disease and mild cognitive impairment. Ann. Neurol. 2009, 66, 200-208. [CrossRef]

18. Prince, M. World Alzheimer Report the Global Impact of Dementia. An Analysis of Prevalence, Incidence, Cost and Trends; Alzheimer's Disease International: London, UK, 2015.

19. Ferri, C.P.; Prince, M.; Brayne, C.; Brodaty, H.; Fratiglioni, L.; Ganguli, M.; Hall, K.; Hasegawa, K.; Hendrie, H.; Huang, Y.; et al. Global prevalence of dementia: A Delphi consensus study. Lancet 2005, 366, 2112-2117. [CrossRef]

20. Brookmeyer, R.; Johnson, E.; Ziegler-Graham, K.; Arrighi, H.M. Forecasting the global burden of Alzheimer's disease. Alzheimer Dement. 2007, 3, 186-191. [CrossRef]

21. Qiu, C.; Winblad, B.; Fratiglioni, L. The age-dependent relation of blood pressure to cognitive function and dementia. Lancet Neurol. 2005, 4, 487-499. [CrossRef]

22. Qiu, C.; Xu, W.; Fratiglioni, L. Vascular and psychosocial factors in Alzheimer's disease: Epidemiological evidence toward intervention. J. Alzheimers Dis. 2010, 20, 689-697. [CrossRef] [PubMed]

23. Kivipelto, M.; Helkala, E.-L.; Laakso, M.P.; Hänninen, T.; Hallikainen, M.; Alhainen, K.; Iivonen, S.; Mannermaa, A.; Tuomilehto, J.; Nissinen, A.; et al. Apolipoprotein E epsilon4 allele, elevated midlife total cholesterol level, and high midlife systolic blood pressure are independent risk factors for late-life Alzheimer disease. Ann. Intern. Med. 2002, 137, 149-155. [CrossRef] [PubMed]

24. Mielke, M.M.; Zandi, P.P.; Sjogren, M.; Gustafson, D.; Östling, S.; Steen, B.; Skoog, I. High total cholesterol levels in late life associated with a reduced risk of dementia. Neurology 2005, 64, 1689-1695. [CrossRef]

25. Atti, A.R.; Palmer, K.; Volpato, S.; Winblad, B.; De Ronchi, D.; Fratiglioni, L. Late-Life Body Mass Index and Dementia Incidence: Nine-Year Follow-Up Data from the Kungsholmen Project. J. Am. Geriatr. Soc. 2008, 56, 111-116. [CrossRef]

26. Kivipelto, M.; Ngandu, T.; Fratiglioni, L.; Viitanen, M.; Kåreholt, I.; Winblad, B.; Helkala, E.-L.; Tuomilehto, J.; Soininen, H.; Nissinen, A. Obesity and Vascular Risk Factors at Midlife and the Risk of Dementia and Alzheimer Disease. Arch. Neurol. 2005, 62, 1556-1560. [CrossRef] [PubMed]

27. Xu, W.; Qiu, C.; Gatz, M.; Pedersen, N.L.; Johansson, B.; Fratiglioni, L. Mid- and late-life diabetes in relation to the risk of dementia: A population-based twin study. Diabetes 2009, 58, 71-77. [CrossRef]

28. Zhong, G.; Wang, Y.; Zhang, Y.; Guo, J.J.; Zhao, Y. Smoking Is Associated with an Increased Risk of Dementia: A Meta-Analysis of Prospective Cohort Studies with Investigation of Potential Effect Modifiers. PLoS ONE 2015, 10, e0118333. [CrossRef] [PubMed]

29. Ownby, R.L.; Crocco, E.; Acevedo, A.; John, V.; Loewenstein, D. Depression and risk for Alzheimer disease: Systematic review, meta-analysis, and metaregression analysis. Arch. Gen. Psychiatry 2006, 63, 530-538. [CrossRef]

30. Hamer, M.; Chida, Y. Physical activity and risk of neurodegenerative disease: A systematic review of prospective evidence. Psychol. Med. 2009, 39, 3-11. [CrossRef]

31. Valenzuela, M.J. Brain reserve and the prevention of dementia. Curr. Opin. Psychiatry 2008, 21, $296-302$. [CrossRef] 
32. Barberger-Gateau, P.; Raffaitin, C.; Letenneur, L.; Berr, C.; Tzourio, C.; Dartigues, J.F.; Alpérovitch, A. Dietary patterns and risk of dementia: The Three-City cohort study. Neurology 2007, 69, 1921-1930. [CrossRef] [PubMed]

33. Caamaño-Isorna, F.; Corral, M.; Montes-Martínez, A.; Takkouche, B. Education and Dementia: A Meta-Analytic Study. Neuroepidemiology 2006, 26, 226-232. [CrossRef] [PubMed]

34. Rose, G. Sick Individuals and Sick Populations. Int. J. Epidemiol. 1985, 14, 32-38. [CrossRef] [PubMed]

35. Norton, S.; Matthews, F.E.; Barnes, D.E.; Yaffe, K.; Brayne, C. Potential for primary prevention of Alzheimer's disease: An analysis of population-based data. Lancet Neurol. 2014, 13, 788-794. [CrossRef]

36. Pennant, M.; Davenport, C.; Bayliss, S.; Greenheld, W.; Marshall, T.; Hyde, C. Community Programs for the Prevention of Cardiovascular Disease: A Systematic Review. Am. J. Epidemiol. 2010, 172, 501-516. [CrossRef] [PubMed]

37. Wu, Y.-T.; Fratiglioni, L.; Matthews, F.E.; Lobo, A.; Breteler, M.M.B.; Skoog, I.; Brayne, C. Dementia in western Europe: Epidemiological evidence and implications for policy making. Lancet Neurol. 2016, 15, 116-124. [CrossRef]

38. Andrieu, S.; Coley, N.; Lovestone, S.; Aisen, P.S.; Vellas, B. Prevention of sporadic Alzheimer's disease: Lessons learned from clinical trials and future directions. Lancet Neurol. 2015, 14, 926-944. [CrossRef]

39. Ashby, E.L.; Kehoe, P.G. Current status of renin-aldosterone angiotensin system-targeting anti-hypertensive drugs as therapeutic options for Alzheimer's disease. Expert Opin. Investig. Drugs 2013, 22, 1229-1242. [CrossRef]

40. Goodison, W.V.; Frisardi, V.; Kehoe, P.G. Calcium channel blockers and Alzheimer's disease: Potential relevance in treatment strategies of metabolic syndrome. J. Alzheimers Dis. 2012, 30 (Suppl. 2), S269-S282. [CrossRef]

41. Van Middelaar, T.; van Vught, L.A.; Moll van Charante, E.P.; Eurelings, L.S.M.; Ligthart, S.A.; van Dalen, J.W.; van den Born, B.J.H.; Richard, E.; van Gool, W.A. Lower dementia risk with different classes of antihypertensive medication in older patients. J. Hypertens. 2017, 35, 2095-2101. [CrossRef]

42. Peters, R.; Beckett, N.; Forette, F.; Tuomilehto, J.; Clarke, R.; Ritchie, C.; Waldman, A.; Walton, I.; Poulter, R.; $\mathrm{Ma}$, S.; et al. Incident dementia and blood pressure lowering in the Hypertension in the Very Elderly Trial cognitive function assessment (HYVET-COG): A double-blind, placebo controlled trial. Lancet Neurol. 2008, 7, 683-689. [CrossRef]

43. Van Middelaar, T.; van Vught, L.A.; van Gool, W.A.; Simons, E.M.F.; van den Born, B.H.; Moll van Charante, E.P.; Richard, E. Blood pressure-lowering interventions to prevent dementia: A systematic review and meta-analysis. J. Hypertens. 2018, 36, 1780-1787. [CrossRef] [PubMed]

44. Sprint Mind Investigators for the SPRINT Research Group. Effect of Intensive vs. Standard Blood Pressure Control on Probable Dementia: A Randomized Clinical Trial. JAMA 2019, 321, 553-561. [CrossRef] [PubMed]

45. Yang, Y.; Song, W. Molecular links between Alzheimer's disease and diabetes mellitus. Neuroscience 2013, 250, 140-150. [CrossRef]

46. Moreira, P.I. Alzheimer's disease and diabetes: An integrative view of the role of mitochondria, oxidative stress, and insulin. J. Alzheimers Dis. 2012, 30 (Suppl. 2), S199-S215. [CrossRef] [PubMed]

47. Areosa, S.A.; Vernooij, R.W.M.; Harmand, M.G.C.; Martinez, G. Effect of the treatment of Type 2 diabetes mellitus on the development of cognitive impairment and dementia. Cochrane Database Syst. Rev. 2017, CD003804. [CrossRef] [PubMed]

48. Launer, L.J.; Miller, M.E.; Williamson, J.D.; Lazar, R.M.; Gerstein, H.C.; Murray, A.M.; Sullivan, M.; Horowitz, K.R.; Ding, J.; Marcovina, S.; et al. Effects of intensive glucose lowering on brain structure and function in people with type 2 diabetes (ACCORD MIND): A randomised open-label substudy. Lancet Neurol. 2011, 10, 969-977. [CrossRef]

49. ADVANCE Management Committee. Study rationale and design of ADVANCE: Action in diabetes and vascular disease-preterax and diamicron MR controlled evaluation. Diabetologia 2001, 44, 1118-1120. [CrossRef]

50. Abbatecola, A.M.; Rizzo, M.R.; Barbieri, M.; Grella, R.; Arciello, A.; Laieta, M.T.; Acampora, R.; Passariello, N.; Cacciapuoti, F.; Paolisso, G. Postprandial plasma glucose excursions and cognitive functioning in aged type 2 diabetics. Neurology 2006, 67, 235-240. [CrossRef]

51. McGuinness, B.; Craig, D.; Bullock, R.; Passmore, P. Statins for the prevention of dementia. Cochrane Database Syst. Rev. 2016, CD003160. [CrossRef] 
52. Grundy, S.M.; Stone, N.J.; Bailey, A.L.; Beam, C.; Birtcher, K.K.; Blumenthal, R.S.; Braun, L.T.; De Ferranti, S.; Faiella-Tommasino, J.; Forman, D.E.; et al. 2018 AHA/ACC/AACVPR/AAPA/ABC/ACPM/ADA/AGS/APhA/ASPC/NLA/PCNA Guideline on the Management of Blood Cholesterol. Circulation 2018. [CrossRef]

53. Voss, M.W.; Nagamatsu, L.S.; Liu-Ambrose, T.; Kramer, A.F. Exercise, brain, and cognition across the life span. J. Appl. Physiol. 2011, 111, 1505-1513. [CrossRef] [PubMed]

54. Brasure, M.; Desai, P.; Davila, H.; Nelson, V.A.; Calvert, C.; Jutkowitz, E.; Butler, M.; Fink, H.A.; Ratner, E.; Hemmy, L.S.; et al. Physical Activity Interventions in Preventing Cognitive Decline and Alzheimer-Type Dementia: A Systematic Review. Ann. Int. Med. 2018, 168, 30-38. [CrossRef] [PubMed]

55. Luchsinger, J.A.; Reitz, C.; Honig, L.S.; Tang, M.-X.; Shea, S.; Mayeux, R. Aggregation of Vascular Risk Factors and Risk of Incident Alzheimer's Disease. Neurology 2005, 65, 545-551. [CrossRef]

56. Yaffe, K. Metabolic syndrome and cognitive disorders: Is the sum greater than its parts? Alzheimer Dis. Assoc. Disord. 2007, 21, 167-171. [CrossRef] [PubMed]

57. Moll van Charante, E.P.; Richard, E.; Eurelings, L.S.; van Dalen, J.W.; Ligthart, S.A.; van Bussel, E.F.; Hoevenaar-Blom, M.P.; Vermeulen, M.; van Gool, W.A. Effectiveness of a 6-year multidomain vascular care intervention to prevent dementia (preDIVA): A cluster-randomised controlled trial. Lancet 2016, 388, 797-805. [CrossRef]

58. Ngandu, T.; Lehtisalo, J.; Solomon, A.; Levälahti, E.; Ahtiluoto, S.; Antikainen, R.; Bäckman, L.; Hänninen, T.; Jula, A.; Laatikainen, T.; et al. A 2 year multidomain intervention of diet, exercise, cognitive training, and vascular risk monitoring versus control to prevent cognitive decline in at-risk elderly people (FINGER): A randomised controlled trial. Lancet 2015, 385, 2255-2263. [CrossRef]

59. Andrieu, S.; Guyonnet, S.; Coley, N.; Cantet, C.; Bonnefoy, M.; Bordes, S.; Bories, L.; Cufi, M.-N.; Dantoine, T.; Dartigues, J.-F. Effect of long-term omega 3 polyunsaturated fatty acid supplementation with or without multidomain intervention on cognitive function in elderly adults with memory complaints (MAPT): A randomised, placebo-controlled trial. Lancet Neurol. 2017, 16, 377-389. [CrossRef]

60. Hill, A.B. The Environment and Disease: Association or Causation? Proc. R. Soc. Med. 1965, 58, $295-300$. [CrossRef]

61. Viswanathan, A.; Rocca, W.A.; Tzourio, C. Vascular risk factors and dementia: How to move forward? Neurology 2009, 72, 368-374. [CrossRef]

62. Andrieu, S.; Coley, N.; Aisen, P.; Carrillo, M.C.; DeKosky, S.; Durga, J.; Fillit, H.; Frisoni, G.B.; Froelich, L.; Gauthier, S.; et al. Methodological Issues in Primary Prevention Trials for Neurodegenerative Dementia. J. Alzheimer Dis. 2009, 16, 235-270. [CrossRef] [PubMed]

63. Richard, E.; Andrieu, S.; Solomon, A.; Mangialasche, F.; Ahtiluoto, S.; Moll van Charante, E.P.; Coley, N.; Fratiglioni, L.; Neely, A.S.; Vellas, B.; et al. Methodological challenges in designing dementia prevention trials-The European Dementia Prevention Initiative (EDPI). J. Neurol. Sci. 2012, 322, 64-70. [CrossRef] [PubMed]

64. Kennelly, S.P.; Lawlor, B.A.; Kenny, R.A. Blood pressure and the risk for dementia-A double edged sword. Ageing Res. Rev. 2009, 8, 61-70. [CrossRef] [PubMed]

65. Kang, Y.-Y.; Wang, J.-G. The J-Curve Phenomenon in Hypertension. Hypertens. Cardiovasc. Dis. 2016, 4, 249-260.

66. Emmerzaal, T.L.; Kiliaan, A.J.; Gustafson, D.R. 2003-2013: A decade of body mass index, Alzheimer's disease, and dementia. J. Alzheimers Dis. 2015, 43, 739-755. [CrossRef] [PubMed]

67. Kivipelto, M.; Helkala, E.L.; Laakso, M.P.; Hanninen, T.; Hallikainen, M.; Alhainen, K.; Soininen, H.; Tuomilehto, J.; Nissinen, A. Midlife vascular risk factors and Alzheimer's disease in later life: Longitudinal, population based study. BMJ 2001, 322, 1447-1451. [CrossRef]

68. McCambridge, J.; Witton, J.; Elbourne, D.R. Systematic review of the Hawthorne effect: New concepts are needed to study research participation effects. J. Clin. Epidemiol. 2014, 67, 267-277. [CrossRef]

69. Dehnel, T. The European Dementia Prevention Initiative. Lancet Neurol. 2013, 12, 227-228. [CrossRef]

70. Aisen, P.S.; Andrieu, S.; Sampaio, C.; Carrillo, M.; Khachaturian, Z.S.; Dubois, B.; Feldman, H.H.; Petersen, R.C.; Siemers, E.; Doody, R.S.; et al. Report of the task force on designing clinical trials in early (predementia) AD. Neurology 2011, 76, 280-286. [CrossRef] 
71. Cupples, L.A.; A Farrer, L.A.; Sadovnick, A.D.; Relkin, N.; Whitehouse, P.; Green, R.C. Estimating risk curves for first-degree relatives of patients with Alzheimer's disease: The REVEAL study. Genet. Med. 2004, 6, 192-196. [CrossRef]

72. Barnes, D.E.; Covinsky, K.E.; Whitmer, R.A.; Kuller, L.H.; Lopez, O.L.; Yaffe, K. Predicting risk of dementia in older adults: The late-life dementia risk index. Neurology 2009, 73, 173-179. [CrossRef] [PubMed]

73. Kivipelto, M.; Ngandu, T.; Laatikainen, T.; Winblad, B.; Soininen, H.; Tuomilehto, J. Risk score for the prediction of dementia risk in 20 years among middle aged people: A longitudinal, population-based study. Lancet Neurol. 2006, 5, 735-741. [CrossRef]

74. Richard, E.; Kuiper, R.; Dijkgraaf, M.G.; Van Gool, W.A. Evaluation of Vascular care in Alzheimer's disease. Vascular care in patients with Alzheimer's disease with cerebrovascular lesions-a randomized clinical trial. J. Am. Geriatr. Soc. 2009, 57, 797-805. [CrossRef] [PubMed]

75. Mukadam, N.; Sommerlad, A.; Huntley, J.; Livingston, G. Population attributable fractions for risk factors for dementia in low-income and middle-income countries: An analysis using cross-sectional survey data. Lancet Glob. Health 2019, 7, e596-e603. [CrossRef]

76. Global Digital Population as of January 2019. Available online: https://www.statista.com/statistics/617136/ digital-population-worldwide/ (accessed on 11 June 2019).

77. Richard, E.; Jongstra, S.; Soininen, H.; Brayne, C.; Van Charante, E.P.M.; Meiller, Y.; Van Der Groep, B.; Beishuizen, C.R.L.; Mangialasche, F.; Barbera, M.; et al. Healthy Ageing Through Internet Counselling in the Elderly: The HATICE randomised controlled trial for the prevention of cardiovascular disease and cognitive impairment. BMJ Open 2016, 6, e010806. [CrossRef] [PubMed]

78. Impact of Lifestyle Modification on Prevention of Dementia, Chronic Kidney Disease, Diabetes, Chronic Obstructive Pulmonary Disease, Cancers and Cardiovascular Disease in a Thai General Population: Cluster Randomized Controlled Trial. Available online: https://clinicaltrials.gov/ct2/show/NCT02967406 (accessed on 11 June 2019).

79. Heffernan, M.; Andrews, G.; Fiatarone Singh, A.F.; Valenzuela, M.; Anstey, K.J.; Maeder, A.; McNeil, J.; Jorm, L.; Lautenschlager, N.; Sachdev, P.; et al. Maintain Your Brain: Protocol of a 3-Year Randomized Controlled Trial of a Personalized Multi-Modal Digital Health Intervention to Prevent Cognitive Decline Among Community Dwelling 55 to 77 Year Olds. J. Alzheimer Dis. 2018, 1-17. [CrossRef] [PubMed]

80. PRODEMOS Study. Available online: https://www.prodemos-project.eu/consortium/academic-medicalcentre-amsterdam/ (accessed on 11 June 2019).

81. Kivipelto, M.; Mangialasche, F.; Ngandu, T. World Wide Fingers Network. World Wide Fingers will advance dementia prevention. Lancet Neurol. 2018, 17, 27. [CrossRef]

82. Rose, G. Strategy of prevention: Lessons from cardiovascular disease. Br. Med. J. (Clin. Res. Ed.) 1981, 282, 1847-1851. [CrossRef]

83. Norrving, B.; Barrick, J.; Davalos, A.; Dichgans, M.; Cordonnier, C.; Guekht, A.; Kutluk, K.; Mikulik, R.; Wardlaw, J.; Richard, E.; et al. Action Plan for Stroke in Europe 2018-2030. Eur. Stroke J. 2018, 3, 309-336. [CrossRef]

(C) 2019 by the authors. Licensee MDPI, Basel, Switzerland. This article is an open access article distributed under the terms and conditions of the Creative Commons Attribution (CC BY) license (http://creativecommons.org/licenses/by/4.0/). 